Photonirvachak

Journal of the Indian Society of Remote Sensing, Vol. 33, No. 1, 2005

\title{
ECO-GEOMORPHOLOGICAL ZONATION OF THE BANGARAM REEF, LAKSHADWEEP
}

\author{
BENIDHAR DESHMUKH, ANJALI BAHUGUNA*@, SHAILESH NAYAK, \\ V.K. DHARGALKAR* AND T.G. JAGTAP* \\ Space Applications Centre, Indian Space Research Organisation, Ahmedabad- 380 015, Gujarat, India \\ National Institute of Oceanography, Dona Paula - Goa, India \\ CCorresponding author : anjali@sac.isro.org
}

\begin{abstract}
Coral reefs, which are known for rich biological diversity and productivity, are being threatened throughout the world by various natural and anthropogenic activities. The present study concentrates on establishing methodology to zone the geo-morphological and ecological zones of the Bangaram reef (of atoll type), Lakshadweep islands, using remotely sensed data and adequately supported by field data. Classification system has been evolved to zone the reefs. Comparative studies have also been carried out using image processing techniques in order to establish the suitable technique for studying the Indian reefs. The IRS LISS III images representing three different tidal conditions of the period 1998-2000 were analyzed. The unsupervised classification of both the raw images as well as principal component images gave similar information. The classified product was subjected to contextual editing. Misclassification among various classes was found to increase with the increase in the depth of the water column present over the reef. The zones identified on the image are central deep lagoon, reef knolls (rising steeply from the central deep lagoon floor), reef edge, reef platform, coralline shelf, broad shallow sandy-bottomed lagoon, beach and two islets. The zonation has helped in getting information on the presence of live corals on the Bangaram reef. This kind of study is a valuable input in assessing the health of the reefs and its diversity.
\end{abstract}

\section{Introduction}

Coral reefs rank highest in the sensitivity ranking for coastal ecosystems and habitats (Anon., 1997), due to their fragile nature, coral-algal symbiotic relationship and diverse reef flora and fauna. They cover $\sim 0.17 \%$ of the ocean floor and are home to $\sim 1 / 4^{\text {th }}$ of all marine species (maximum of 9 million species), with the largest number of coral genera being found in the Indian and tropical 
western Pacific oceans. The vast diversity of the animal and plant species that contributes to its system and the genetic heritage that it represents is increasingly at risk. It has been estimated that unless steps are taken to slow coral reef destruction, up to 1.2 million reef species alone could be extinct within 40 years. A study conducted by Bryant et al. (1998) estimated that about $58 \%$ of the world's reefs are at high and medium risk especially due to over-exploitation and other anthropogenic factors. According to the same study it is estimated that around $68 \%$ of Indian reefs are at high risk. The conservation of the coral reef is therefore, identified as a priority in the World Conservation Strategy (IUCN, 1980). Environmentally effective coral reef management depends upon accurate and comprehensive scientific data on which policy decisions can be made.

Coral reefs generally exist in clear waters, which are highly suited to optical remote sensing. Baseline data for coral reefs of the entire Indian coast has been generated using satellite data, wherein, extent, type of reefs and few broad geomorphological zones were identified such as reef flat, mud and sand depositions on the reef, vegetation on reef, etc. (Bahuguna and Nayak, 1998). An attempt has also been made to zone Kalubhar reef of the Gulf of Kachchh eco-geomorphologically (Nayak et al., 1996, Navalgund and Bahuguna, 1999). The ecological component of the reef included algal ridge, seagrass, seaweed Sargassum, dense and sparse algae on the mud over reef flat, etc. (Nayak and Bahuguna, 2001). Optical remote sensing has however only been successful in shallow reef flat environments. Coral reefs environment are optically, spatially and temporally complex environments presenting difficulties in extracting information on ecology and vitality of coral reef communities. The high species diversity is reflected in the wide array of optical signatures emanating from the living reef surface. Because a large portion of the coral reef habitat is composed of living organisms, much of the upcoming reef signal is a function of the biooptical state of the community. It is a blend of many complex spectral signatures caused by the spectral and spatial complexity of the habitat, reef geomorphology and the optical properties of the overlying water column. Coral reefs exhibit distinctive patterns of morphological and ecological zones, which are determined by the morphology; spatial and temporal variations; interaction between the hydrodynamic processes (waves and tides); geomorphic process (sediment generation, sorting and transport) and ecological process (abundance, composition, growth form, cover and productivity in biological communities). Communities of species and/or substrata often exhibit considerable variability and several distinct communities may inhabit each geomorphological zone. Geomorphological zones tend to have more distinct boundaries than ecological habitats that tend to exhibit change along gradients (e.g., progressive changes in species composition with changing depths). This kind of eco-geomorphological zoning is also termed as coral reef habitat zoning (Mumby and Green, 2000). It attains great value in managing the reefs particularly in assessing the health of the reefs, assessing biodiversity at ecosystem, community and at species level.

\section{Study Area}

Bangaram reef of the northern group of Lakshadweep islands lies northeastwards of the Agatti island. It has an extensive lagoon $(10.6 \mathrm{~km}$ in size), two islands (Bangaram and Tinnakara) and two islets northeast of Tinnakara (Parali I \& Parali II). The reef is steep on northern and eastern sides. About eight species of corals are recorded here, dominant of which are Porites, Acropora, Favia and Favites (based on ground observations). Seaweeds such as Caulerpa sertularioides, Halimeda, Hypnea valentiae, Champia, Ulva fasciata, Enteromorpha, Chaetomorpha and Cladophora are dominant in the Bangaram reef (.based on ground observations). Seagrass Cymodocea rotundata inhabits the lagoonal region. The most conspicuous feature of Bangaram reef is the presence of a number of coral knolls in the lagoonal regions. 


\section{Data and Methodology}

IRS 1D LISS III data (bands green, red and near infra-red) of the period 1998-2000 representing different tidal conditions was used to study the ecogeomorphological zones of the Bangaram coral reef. Tidal condition was estimated from the tidal data of Minicoy Island. Low tidal condition (Fig. 1a) prevailed on $30 \mathrm{Jan} 2000$ (0.88 $\mathrm{m}$ at $1030 \mathrm{hrs})$, medium tide (Fig. lb) on 5 April 1999 (0.93 m at $1030 \mathrm{hrs})$ and high tide (Fig. 1 c) on 26 March 1998 (1.2 m at $1030 \mathrm{hrs}$ ). Extensive field data was collected by snorkeling over the reef, for establishing signatures of various eco-geomorphological zones. The deeper lagoonal portions were surveyed by boat and individual knolls were surveyed by snorkeling. Live coral cover (in percentage and type), algal growth (in percentage and type), substrate type, depth, etc., were noted for each data point. A hand held GPS device was used for establishing geographical locations in the lagoonal and reefareas.

The classification system for zoning the reefs based on geomorphological and ecological components using satellite data has been evolved for the entire Indian coral reefs with region-specific modifications.

Image correction (radiometric and geometric) and enhancement (Principal Component AnalysisPCA), training and signature evaluation were performed prior to classification. The PCA product gave a better visual perception and thereby better signature sets. The classified products were then subjected to contextual editing with an aim to achieve better accuracy. Contextual editing is the application of decision rules where merging of the classes takes places. Here, the problem was spectral confusion between deep lagoon and reef front, reef flat and lagoonal coral knolls, reef crest and lagoonal coral knolls, and, coralline shelf and deep lagoon. The context applied was that the, i) deep lagoonal area does not occur in the reef front region, ii) reef flat and reef crest do not occur in the lagoonal areas and iii) coralline shelf does not occur in the lagoonal area. Therefore, the decision rule applied was that i) lagoonal area falling in the reef front should be
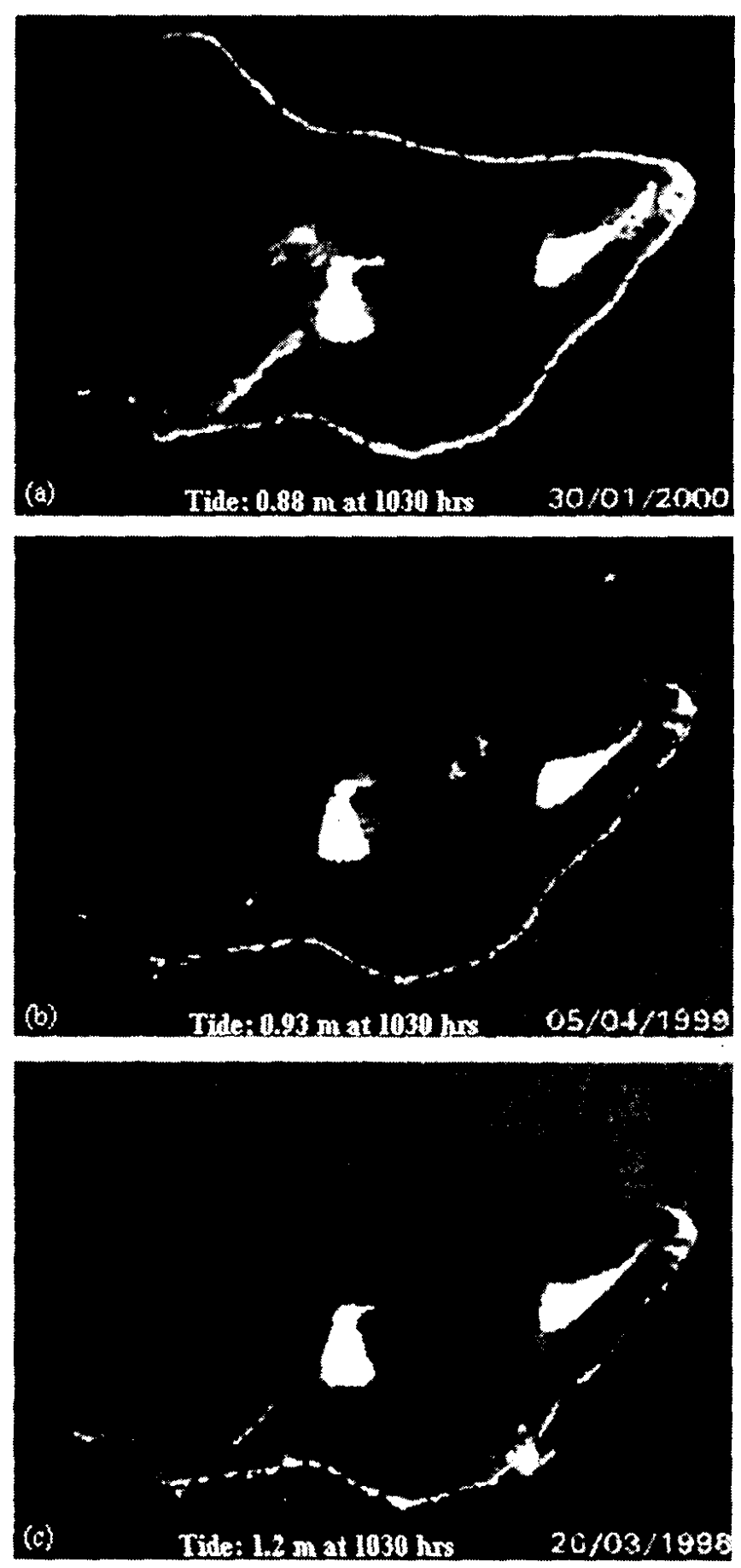

Fig. la-c. NIR bands $(0.77-0.85 \mu \mathrm{m})$ of the three date images showing different tidal conditions over the reef. The bright objects represent features that get exposed during low tide. 
recoded as reef front, ii) reef flat and reef crest falling in the lagoonal region should be recoded as coral knolls and iii) Coralline shelf falling in the lagoonal region should be recoded as deep lagoon. Overall classification accuracy and Kappa test were performed to ascertain accuracy. It should be mentioned here that the unsupervised classification method was able to classify all the zones with considerable accuracy (the maps were also verified on ground) and therefore, the need to carry out supervised classification was not felt. Three maps pertaining to the three periods were generated.

\section{Results and Discussion}

The classified products of geometrically and radiometrically corrected image of Bangaram island and the PCA image (also corrected geometrically and radiometrically) gave similar results. In the PCA classified products of all periods linear features like beach surrounding the islands and reef crest were not classified properly. Merging of coralline shelf with deep lagoon was also observed in the PCA image of the year 2000 (Fig. 2). Out of the two classification methods, it has been observed that the unsupervised classification is best for coral reef regions with some contextual editing. The comparison between different methods and different periods is explained in the following table in terms of overall accuracy and Kappa coefficient $(K)$.

\begin{tabular}{|c|c|c|c|}
\hline & Year & $\begin{array}{c}\text { Unsuper- } \\
\text { vised CL }\end{array}$ & $\begin{array}{c}\text { PCA } \\
\text { Unsuper- } \\
\text { vised CL }\end{array}$ \\
\hline \multirow{2}{*}{$\begin{array}{c}\text { Overall Accuracy } \\
\text { (in\%) }\end{array}$} & 2000 & $\mathbf{8 1 . 4 7}$ & 83.2 \\
\cline { 2 - 4 } & 1999 & $\mathbf{6 7}$ & 68.9 \\
\cline { 2 - 4 } & 1998 & $\mathbf{7 0}$ & 71.0 \\
\hline \multirow{2}{*}{ Kappa } & 2000 & $\mathbf{0 . 8 4}$ & $\mathbf{0 . 8 4}$ \\
\cline { 2 - 4 } & 1999 & 0.72 & 0.72 \\
\cline { 2 - 4 } & 1998 & 0.78 & 0.74 \\
\hline
\end{tabular}

Overall accuracy is a measure of accuracy for the whole image across all classes. However, it ignores the off-diagonal elements (the errors of omission and commission) and different values of overall accuracy cannot be compared easily if a different number of accuracy sites were used to test each classification. In a Kappa analysis, off-diagonal elements are incorporated as a product of the row and column marginal totals, which can be computed in a standard spreadsheet package. $K$ is generally less than the overall accuracy unless the classification is exceptionally good (i.e., the number of off-diagonal elements is very low) (Mumby and Green, 2000). The above table substantiates the fact that both the methods are similar with unsupervised classification of standard image being marginally better than the PCA unsupervised classification. Both the overall accuracy and Kappa of the year 2000 image is higher indicating better classification of the image. It should be noted here that out of the three periods images, year 2000 image was of low tide and gave maximum number of classes (even in otherwise submerged areas of other two images). Year 1999 image was cloudier and therefore inaccuracies in classification were more. In this paper, map of year 2000 (containing maximum number of eco-geomorphological classes and the map with maximum accuracy) is being given (Fig. 2).

Eco-geomorphological Zones of Bangaram Reef

The eco-geomorphological zones of the reefare as follows (Fig. 2). The area occupied by various ecological as well as geomorphological zones of Bangaram reef is given as Table 1 .

\section{Coralline shelf}

The zone between seaward edges of the fore reef to the beginning of the escarpment where the insular shelf drops off into deep oceanic water is termed as coralline shelf (Ahmad, 1972). It is the flattened platform between the fore reef/ reef front and deep open ocean waters. Among all the Lakshadweep islands, the coralline shelf joining the two reefs, Bangaram and Agatti is most unique. From the north of Agatti, the shelf extends northwards 


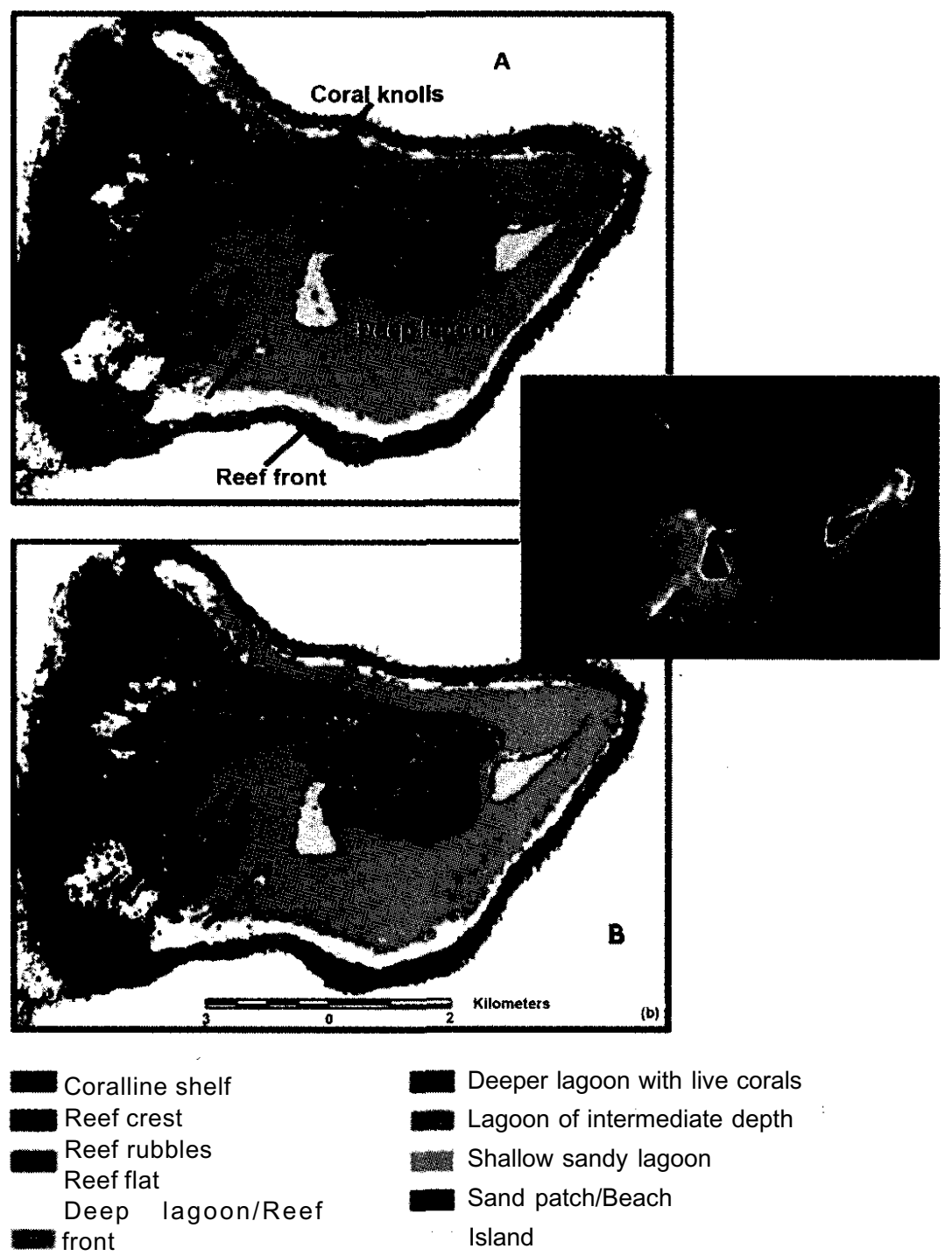

Fig. 2. Classified products of FCC (a) and PC (b). (Source: IRS-ID LISS III data of 30 January 2000). Ground truth points are shown (GPS coordinates) on the IRS-1D LISS III image of Bangaram reef dated 30 January 2000.

and joins the western portion of the Bangaram reef. The shelf is wider on the western region and is linear and parallel in the rest of the regions.

\section{Reef Front}

The reef front zone is an extension of the buttresses and surge channels of the reef margin, is always covered with water, and is not just awash. The location where the features of the channel and buttress system end marks the lower boundary of the steeply sloping reef front. The richest assortment of reef life grows on the reef front and reef margin. The southwestern portion of the reef front was surveyed by boat. During low tide about $1 \mathrm{~m}$ water remains over the reef front. 4-5 species of live corals were observed ( $40 \%$ cover) in about $10 \mathrm{~m} \mathrm{x} 10 \mathrm{~m}$ area surveyed, where the species of Porites and Favia were the dominants. Coral bleaching was also observed along with coral debris and dead corals. 
Table 1: Area occupied by various ecogeomorphological zones of Bangaram Reef

\begin{tabular}{|l|c|}
\hline Category & Area in hectare \\
\hline Coralline shelf & 990.7 \\
\hline Reef crest/coral knolls & 160.8 \\
\hline Reef rubbles & 106.9 \\
\hline Reef flat/coral knolls & 584.9 \\
\hline Deep lagoon/Reef front & 821.8 \\
\hline Deeper lagoon with live corals & 671.9 \\
\hline Lagoon of intermediate depth & 172.4 \\
\hline Shallow sandy lagoon & 1351.5 \\
\hline Sand patch/Beach & 53.5 \\
\hline Island & 103.9 \\
\hline Total & $\mathbf{5 0 1 8 . 3}$ \\
\hline
\end{tabular}

\section{Reef Crest}

Reef crest is the flattened, emergent (especially during low tides) or nearly emergent segment of a reef. This zone lies between the reef flat and reef front zones and is clearly distinguishable on the satellite zone due to the breaking waves at its seaward edge. The Bangaram reef has linear and clear reef crest on almost all the sides of the reef.

\section{Reef Rubble}

It is a dead unstable coral rubble zone often colonized with filamentous or other macroalgae and occurs landward of the reef crest. This zone was differentiated only in the low tide image of the year 2000. It occurs landward to the reef crest on all sides except the western portion where it is conspicuously absent. The zone is broader than the reef crest and signature of vegetation was observed over it in the January 2000 image, but could not be validated, as the vegetation was absent in April 2001 when the ground data was collected.

\section{Reef flat}

Reef flat is present between the seaward edge of a lagoon floor and the landward edge of the reef crest or reef rubble (in case of Bangaram reef). Reef flat of Bangaram comprises shallow pools where live corals density is $5 \%$ (this zone has overall live coral density around $2 \%$ ), sand rubble, coral debris and shingles.

\section{Lagoon}

Lagoon of the Bangaram reef (occupying a large area of $10 \times 6 \mathrm{~km}$ ) has been further classified based on depth and substrate into shallow sandy lagoon, lagoon of intermediate depth, deeper lagoon with live corals, deep lagoon and coral knolls in the deep lagoon.

\section{(a) Shallow sandy lagoon}

Shallow sandy lagoon making up the maximum area is present adjacent to the reef flat on the landward side in a lateral U-shape encompassing northern, eastern and southern portions and is conspicuously absent on the western side. The depths here are about $0.5-1.5 \mathrm{~m}$ in low tides, comprising white coralline fine textured sand with rubbles, and occasional live coral colonies with algae.

(b) Lagoon of intermediate depth

8-10 m depth lagoon makes up the category lagoon of intermediate depth in Bangaram. The lagoon comprises live coral colonies of $(5-10 \%$ coral density) and occurs as small irregular patches in the southwestern side.

(c) Deeper lagoon with live corals

The depth here was measured to be $10-20 \mathrm{~m}$ and significantly comprises live corals of mostly Acropora and Goniopora with associates like Favia, Favites and Porites. The size of the Acropora 
Eco-geomorphological

colony was 3-4 m. At the time of survey it was observed that the corals of this region were having protruded polyps (showing feeding stage) and the entire patch was covered with bloom (blue-green algae). This type of lagoon is present as a large patch in between the Bangaram and Tinnakara islands also making up the seaward edge of the deep lagoon everywhere.

\section{(d) Deep lagoon}

The central portion of the lagoon is deep (20$50 \mathrm{~m})$.

(e) Deep lagoon with Coral Knolls

The coral knolls inhabiting the deep lagoon have been differentiated as small white patches clearly on the satellite image. The knolls are circular in shape (with a diameter of 10-15 m) rising steeply from the lagoon floor and remain submerged at 0.5 $1.5 \mathrm{~m}$ depths even at low tides. These knolls are rich in coral diversity (9 type of hard corals) and density (70-80\% live coral cover on average).

\section{Conclusion}

Earlier studies carried out using RS data pertained to generating baseline data and included classifying the reefs into type of reefs and zoning the reefs into reef flat, reef vegetation, lagoon (i.e. broad geomorphological zone and a single ecological zone by way of reef vegetation). IRS LISS III image coupled with extensive ground survey helped in zoning the geomorphological zones (coralline shelf, reef front, reef rubble, reef flat, shallow sandy lagoon, lagoon of intermediate depth and deep lagoon, coral knolls in the deep lagoon), and the ecological zones of the reef (live corals in the intermediate depth lagoon, and live corals in the coral knolls). The highlight of this study was the mapping of live corals zone in the reef as well as lagoon. The unique part of the Bangaram atoll is the presence of coral knolls in the lagoonal area (coral knolls are only found in Bangaram and Minicoy among all the Lakshadweep islands). The
Zonation of the Bangaram Reef...

105

classification system has been evolved during this study that helped in zoning the reefs.

The unsupervised classification of the corrected LISS III image was marginally better than the PCA corrected LISS III image for zoning the coral reefs (although both gave similar overall accuracy and Kappa coefficient). Unsupervised classification satisfied the criteria of ecogeomorphological zonation using satellite data. Low tide image of the year 2000 gave maximum number of classes and maximum accuracy $(\sim 81 \%)$.

The limitation in classification which arises due to the presence of water column over the reef and lagoon categories can be minimized by subjecting the image to water column correction and obtaining the depth invariant bottom index (based on the reflective properties of the bottom material). It is felt that this will help in clearly delineating the coral knolls, intermittent sandy bottom in the deep lagoon area, reef crest and reef front and clear distinction between reef front and the coralline shelf. It is therefore concluded that for better zoning of the reefs water column correction technique should be applied.

\section{Acknowledgements}

The authors are extremely grateful to the Department of Ocean Development for providing necessary funds to carry out this work. Thanks are due to Dr. Ismael Koya, Deputy Director, Department of Science and Technology, Union Territory of Lakshadweep and his team, for providing dedicated support during ground survey.

\section{References}

Ahmad, E. (1972). Coastal Geomorphology of India, Orient Longman, New Delhi.

Anonymous, (1997). Malacca Straits Environmental Profile. In 'Seshaiyana' ENV1S Newsletter on Estuaries, Mangroves, Coral reefs and Lagoons. 6 (2): 16. 
Bahuguna A. and Nayak S. (1998). Coral reefs of the Indian coast, Scientific Note, SAC/RSA/RSAG/ DOD-COS/SN/16/97 Space Applications Centre, Ahmedabad: 56.

Bryant, D., Burke, L., McManus J. and Spalding M. (1998). Reefs at risk. A map based indicator of threats to the world's coral reefs. World Resources Institute, Washington, D.C., pp. 20-21.

IUCN (1980). World conservation strategy. Coral Reefs. Ecosystem of the world, Vol. 25. (Ed: Z. Dubinsky (Elsevier Science Publishers B.V. 1990), pp. 458.

Mumby, P.J. and Green, E.P. (2000). Field Survey: Building the link between image and reality and Mapping coral reefs and macroalgae. In Remote Sensing for Tropical Coastal Management. (Ed: A. Edwards), UNESCO Publishing, pp. 64, 155.
Nayak S. and Bahuguna A. (2001). Application of RS data to Monitor Mangroves and Other Coastal Vegetation of India, In Indian Jour. Marine Sciences, 30(4): 195-213.

Nayak, S.R., Chauhan, P., Chauhan, H.B., Bahuguna, A. and Narendra Nath, A. (1996). IRS-1C applications for coastal zone management, Current Science, 70: 614-618.

Navalgund R.R. and Bahuguna A. (1999). Applications of remote sensing and GIS in coastal zone management and conservation: Indian experience, Proc: U.N. ESCAP/ISRO Science Symposium, On Space Technology for improving Quality of Life in Developing Countries: a perspective for the next millennium, held at New Delhi from Nov. 15-17 1999, pp. 121-146. 